\title{
Descrevendo o uso dos computadores nas escolas públicas da Paraíba
}

\author{
Title: Describing computer usage in public schools of Paraíba
}

\author{
Adriana Carla Damasceno \\ Centro de Ciência e Tecnologia Agroalimentar \\ Universidade Federal de Campina Grande \\ Pombal - Pb, Brasil \\ adrianacarla@ccta.ufcg.edu.br \\ Rafael Andrade \\ Centro de Ciência e Tecnologia Agroalimentar \\ Universidade Federal de Campina Grande \\ Pombal - Pb, Brasil \\ rafael.fernandes.andadrade@gmail.com \\ Israel Almeida \\ Centro de Ciência e Tecnologia Agroalimentar \\ Universidade Federal de Campina Grande \\ Pombal - Pb, Brasil \\ israelfla81@gmail.com
}

\author{
Mayrlla Lopes \\ Centro de Ciência e Tecnologia Agroalimentar \\ Universidade Federal de Campina Grande \\ Pombal - Pb, Brasil \\ mayrla.karla.lopes@gmail.com
}

\author{
Silvana Nóbrega \\ Centro de Ciência e Tecnologia Agroalimentar \\ Universidade Federal de Campina Grande \\ Pombal - Pb, Brasil \\ silvananobreri@hotmail.com
}

Resumo $O$ uso dos computadores em escolas públicas constitui um grande aliado no aprendizado dos alunos. Eles fornecem meios de ilustrar conceitos e acesso a uma gama de informações. No entanto, a frequência de uso dos computadores é baixa na maioria das escolas públicas. Este trabalho busca identificar o perfil de uso dos computadores para alunos e professores de escolas. Para isso, foram aplicados 735 questionários para alunos e 134 questionários para professores de escolas públicas do Alto Sertão da Paraíba. Os dados obtidos foram resumidos e testes estatísticos foram realizados para identificar relações entre as variáveis estatísticas Infraestrutura, Conhecimento em informática e Uso dos computadores. Constatamos que os laboratórios das escolas são usados diariamente, a maioria dos professores possui Internet e computador em casa, a maioria dos alunos possui smartphone e usa a Internet. Além disso, os professores e os alunos estão submetidos a uma alta infraestrutura e alto conhecimento em informática, mas pouco menos da metade dos alunos relata ter aulas nos laboratórios de informática frequentemente. Na análise estatística, somente o uso dos computadores e o conhecimento em informática dos alunos são relacionados estatisticamente.

Palavras-Chave: Educação, Infraestrutura de Informática, Laboratório de Informática, Uso dos Computadores, Escolas Públicas

\footnotetext{
Abstract The usage of computers in public schools helps the students learning. Computers provide ways to illustrate concepts and access to a wide range of information. However, the computers are not used in most public schools. This work intends to identify how computers are used in public schools from the Paraiba countryside. For this, we applied 735 forms for students and 134 forms for teachers. We summarized data and applied statistical tests to identify correlations among the statistical variables Knowledge in computer technology, Informatics infrastructure, and Computer usage. We found that informatics laboratories have daily usage, the majority of teachers has Internet access and computer at home, the majority of students has smartphones and they use Internet. Besides that, teachers and students that use computers have access to high informatics infrastructure and
} 
high knowledge in computers, but more than a half of the students do not have classes in the informatics laboratory. In the statistical analysis, there is no relation among variables when we analyze data from students and teachers, with exception of informatics knowledge and computer usage for students.

Keywords: Education, Informatics Infrastructure, Informatics Laboratory, Computer Usage, Public Schools 


\section{Introdução}

O uso dos computadores é de grande importância para o aprendizado dos alunos em sala de aula. Eles permitem com que o professor utilize ferramentas pedagógicas, como ilustrações, jogos educativos e outras dinâmicas que facilitam o entendimento de novos conceitos. Em adição, eles facilitam o acesso a dados de diferentes localizações geográficas a um baixo custo.

No entanto, observa-se que os computadores não são usados em salas de aula de escolas públicas frequentemente [3]. Os motivos deste desuso nas escolas de diversas cidades é alvo de vários estudos $[1,9,15]$. Dentre as razões mais comuns, estão a falta de infraestrutura de informática disponível, treinamento dos professores em nível pedagógico e em softwares específicos, suporte técnico e cultura ambiental.

O Alto Sertão da Paraíba também foi foco de estudos sobre o desuso de computadores nas escolas públicas. Um pequeno grupo de alunos foi investigado quanto ao seu hábito de uso dos computadores sem a análise de variáveis estatísticas [6]. Além disso, o perfil de uso dos computadores pelos professores foi analisado em 6 cidades do Sertão Paraibano [5]. Foi constatado que o uso dos computadores pelo professores não é relacionado à infraestrutura das escolas e ao seu conhecimento em informática. Ademais, há uma alta infraestrutura disponível nas escolas, mas os professores usam pouco os computadores.

Este trabalho estende o trabalho de Damasceno et al [5] através da aplicação de questionários para os alunos da mesma região. Além disso, comparamos os dados anteriores dos professores com os dados dos alunos recém obtidos para melhorar a caracterização das informações obtidas. Dentre as contribuições detalhadas, podemos citar: (i) apresentação dos dados dos alunos das escolas, (ii) adição de uma questão de inferência para professores e alunos, (iii) apresentação de informações sobre tempo de trabalho dos professores nas escolas, (iv) análise estatística dos dados dos alunos e (v) comparação dos dados obtidos com os valores obtidos em uma pesquisa nacional.

Para isso, aplicamos 735 questionários para alunos em escolas públicas de seis cidades e realizamos um survey cujo propósito foi estudar a relação entre o hábito do uso dos computadores pelos alunos e professores, a infraestrutura computacional de seus locais de trabalho e o uso dos computadores em salas de aula para cidades do Sertão Paraibano. Com isso, foi possível definir o perfil de uso dos computadores pelos professores e alunos nas escolas públicas destas cidades.

Usamos os dados destes survey para responder às seguintes questões: (1) Como os professores e alunos são avaliados em relação ao conhecimento em informática? (2) Qual o nível da infraestrutura computacional disponível para alunos e professores? (3) Como os professores e alunos usam os computadores durante as aulas? (4) O nível de conhecimento em informática dos professores e alunos é relacionado ao uso dos computadores durante as aulas? (5) A infraestrutura de informática oferecida pelas escolas afeta o uso dos computadores pelos professores e alunos durante as aulas? (6) A infraestrutura de informática oferecida pelas escolas é relacionada ao conhecimento dos professores e alunos?

A partir daí, identificamos o perfil de uso dos computadores, infraestrutura e conhecimento e informática dos professores e alunos nas escolas. A Seção 2 apresenta a fundamentação teórica e trabalhos similares. A Seção 3 detalha a metodologia usada para tratamento dos questionários. Na sequência, a Seção 4 apresenta os resultados da caracterização do uso dos computadores, infraestrutura e conhecimento em informática nas escolas. Finalmente, a Seção 5 contém as conclusões deste trabalho.

\section{Referencial Teórico}

A capacitação dos recursos tecnológicos nas escolas é uma das bases da inclusão digital. Somente a aquisição dessas máquinas não é suficiente porque seu uso só será relevante quando incorporado significativamente às práticas pedagógicas das escolas [11].

A implantação da informática na escola é uma tarefa muito complexa, pois exige que todos os segmentos da escola, incluindo professores, administradores e alunos estejam adequados a este processo de formação de conhecimento. O computador tem o papel de transmitir informações ao usuário e ser uma ferramenta central no processo de construção do conhecimento. Em adição, a implantação dos computadores nas escolas deve estar acompanhada de um preparo dos professores e da comunidade escolar [16].

Por isso, é preciso criar estratégias para que o professor reflita sobre a sua prática e sobre a sua importância nesse novo contexto educacional e social, definido dentro da sociedade da informação e do conhecimento. Nesse ambiente, professores e alunos podem tornar-se sujeitos ativos diante da quantidade de informações recebidas no 
dia-a-dia, uma vez que a legislação garante a formação global dos seres humanos [14].

Vários trabalhos visam levantar o perfil de uso dos computadores pelas escolas públicas, mas nenhum levantou dados sobre o Sertão da Paraíba. De uma forma geral, constata-se o desuso dos laboratórios de informática e a falta de capacitação dos professores. Algumas análises das condições efetivas de uso das salas de informática identificam que as dificuldades são de ordem física, retardos de cronogramas e problemas de instalações de hardware e software nos computadores, além de condições pessoais e profissionais de trabalho do professor [3]. Sendo assim, os professores são desafiados a atualizar seus conhecimentos iniciais e avaliar as mudanças necessárias para inovar suas práticas pedagógicas [10].

O governo lançou o programa Projeto UCA (Um computador por Aluno) que possibilita a distribuição de laptops a professores de escolas públicas. Foram realizados estudos exploratórios que evidenciam as principais dificuldades no uso de computadores pelos professores na cidade de Araucária (PR) e no estado do Tocantins $[1,8]$. Constatou-se que os seguintes fatores limitam o uso dos computadores: experiência pessoal com o uso da tecnologia, formação, suporte técnico e pedagógico no interior da escola e questões de infraestrutura e da cultura da escola.

No entanto, a criação de estratégias de melhoria desse panorama depende da caracterização do uso dos computadores em escolas públicas. Vários trabalhos foram realizados para levantar o perfil de uso desses computadores. Nascimento et al [11] levanta algumas características principais de uso dos laboratórios de informática educativa na cidade de Fortaleza. Com isso, descobriu-se que $81 \%$ dos professores entrevistados relataram que não tinham um horário específico para planejamento de aulas no laboratório.

Silva et al [15] investiga os mecanismos de gestão e uso dos laboratórios de informática em duas escolas públicas de Recife. Eles realizaram entrevistas com os professores para avaliar a necessidade de computadores em sala de aula. Ademais, observações feitas ao cotidiano da escola permitiram constatar que o uso do computador é importante para o aprendizado dos alunos durante as aulas. No entanto, não há o uso efetivo por falta de capacitação dos professores e limitação quanto à quantidade de computadores.

Odorico et al [13] investiga o desuso de laboratórios de informática em duas escolas públicas. Foram aplicados questionários, de onde se pode constatar que a formação inicial do professor não tem influência na adoção da informática no ensino. No entanto, constatou-se a falta de planejamento no processo de uso dos computadores pelos professores, causando desmotivação. Em contrapartida, o estudo de caso realizado com professores de Matemática mostrou resultados positivos na adoção de recursos computacionais em sala de aula.

O Comitê Gestor da Internet [2] realiza pesquisas anuais sobre o uso das Tecnologias de Informação e Comunicação (TIC) nas escolas públicas e particulares brasileiras. São oferecidos dados sobre alunos, professores, coordenadores e diretores das escolas. Além disso, também há informações sobre infraestrutura de informática das escolas, formação de professores, uso de recursos digitais para professores e uso da informática pelos alunos. No ano de 2015, a compra e instalação dos computadores usados nas escolas foi realizada entre 5 e 10 anos atrás para mais de $39 \%$ delas. Ademais, a presença de equipamentos obsoletos está em $81 \%$ das escolas e $41 \%$ das escolas públicas com conexão de Internet possui até 2 Mbps. Infelizmente, não é oferecido um detalhamento sobre cidades do Brasil com uma análise de variáveis estatísticas e testes de inferência, como é feito em nosso trabalho.

Nobre et al [12] apresentou uma pesquisa sobre o uso dos laboratórios de informática no interior do Ceará. Foram entrevistados 51 professores e 18 coordenadores pedagógicos, de laboratório e diretores, além de 15 funcionários das escolas. A maioria dos professores têm mais do que cinco anos de magistério e tende a não usar o computador em sala de aula. Além disso, a maioria dos professores leciona entre duas e cinco disciplinas. Também são apresentados dados sobre o tempo em que ocorreu a última capacitação na área de informática, uso dos laboratórios de informática pelos professores, e razões da falta de uso do laboratório de informática. O motivo mais citado é a insegurança ao trabalhar com o computador. Dentre as diferenças em relação ao nosso trabalho, estão a aplicação dos questionários em uma área geográfica diferente, a falta de análises estatísticas e de informações sobre o perfil de uso dos computadores pelos alunos.

\section{Métodos}

Para levantar o perfil de uso dos computadores pelos professores e alunos de escolas públicas da cidade de Pombal e adjacências, conduzimos um survey crosssectional usando a metodologia descrita em Creswell [4]. Este foi adotado por ser um método econômico de coleta 
de dados, fornecendo tempo de retorno rápido em um ponto do tempo. Adicionalmente, usamos coleta de dados com questionários impressos.

A aplicação dos questionários foi realizada para os professores e alunos, sendo quem em momentos diferentes. Na aplicação para os professores, os próprios entrevistados respondiam às perguntas sem a orientação de entrevistadores. Isto ocorreu porque nem todas as escolas dispunham de acesso à Internet e nosso escopo envolvia várias cidades, o que trazia limitações econômicas e temporais à aplicação dos questionários. Para a entrevista dos alunos, a aplicação dos questionários foi realizada de forma presencial em todas as escolas, também sem uso de Internet.

A caracterização do conhecimento de informática dos alunos foi realizada através da aplicação de um questionário de 16 questões onde cada uma oferecia cinco categorias de respostas: discordo totalmente, discordo parcialmente, indiferente, concordo parcialmente e concordo totalmente. O questionário possui 16 questões relacionadas ao uso dos computadores, infraestrutura de informática das escolas e conhecimentos dos alunos na área de informática. A Figura 1 mostra as questões aplicadas.

1. Tenho conhecimento sobre hardware?

2. Tenho conhecimento sobre software?

3. Sei a diferença entre um periférico de entrada, um periférico de saída e um periférico de entrada e saída?

4. Sei organizar pastas e arquivos em um gerenciador de arquivos (Ex.: Windows Explorer e Konqueror)?

5. Tenho conhecimento técnico dos computadores, como por exemplo resolver problemas de configuração, teclado e acesso à Internet?

6. Sei editar textos no Word, realizando atividades como inserção de nota de rodapé, gráficos, tabelas e marca d'água?

7. Uso com muita frequência no celular aplicativos para redes sociais como o Facebook, What's up, Instagram e Tinder?

8. Já participei de algum curso para usar o computador?

9. Possuo computador em casa?

10. Tenho acesso à Internet em casa?

11. Possuo smartphone?

12. Uso o computador para fazer atividades da escola?

13. A frequência com que assisto aulas no laboratório de informática é alta?

14. Faço trabalhos na escola usando o computador?

15. Meu celular é utilizado mais para acesso à Internet do que para fazer ligações?

16. Meu celular atrapalha meu aprendizado em sala de aula?
O questionário aplicado aos professores é formado por 16 questões com respostas categóricas ( $\mathrm{sim} /$ não). $\mathrm{O}$ objetivo é identificar o conhecimento dos professores em informática, assim como a forma como eles usam os computadores nas aulas. A Figura 2 mostra de que questões são compostas este instrumento.

17. Você possui computador em casa?

18. Você tem acesso à Internet?

19. Você utiliza o computador para auxiliar suas aulas?

20. O computador que você tem acesso na escola é de fácil disponibilidade?

21. A frequência com que você trabalha com os alunos no laboratório de informática é alta?

22. Os alunos colaboram com as atividades desenvolvidas no laboratório de informática?

23. A participação dos professores em cursos e oficinas que auxiliem e orientem a utilização dos recursos computacionais seria importante?

24. Há disponibilidade sua para participar de cursos de capacitação?

25 . Você tem dificuldade em usar o computador?

26. Você já participou de um curso de informática básica?

27. Você já redigiu provas ou textos na escola com uso do computador?

28. Você prepara slides para exibir conteúdos escolares utilizando ferramentas de apresentação eletrônica (Power Point, Slides, etc)?

29. Você tem conhecimento técnico dos computadores, como por exemplo problemas de configuração, teclado e acesso à Internet?

30. Existe algum programa de inclusão digital na escola em que você trabalha?

31. Você já participou de algum curso de capacitação para utilizar a Internet em sua escola?

32. Você acredita que a inclusão digital pode melhorar o seu desempenho docente e dos seus alunos?

Figura 2 Questionário para professores

Para avaliar a infraestrutura computacional disponível para os alunos e professores e a frequência de uso do laboratórios de informática das escolas, os diretores responderam um questionário composto de sete questões, sendo quatro do tipo sim/ não e três abertas. Dependendo da resposta positiva sobre uma questão, algumas perguntas adicionais foram requisitas. As questões estão mostradas na Figura 3.

Figura 1 Questionário para alunos 
33. A escola possui laboratório de informática?

a) Quantos computadores o laboratório possui?

34. O laboratório de informática possui acesso à Internet?

35. Existem funcionários alocados para o conserto dos computadores?

36. Os alunos têm acesso aos computadores na escola?

a) Qual a frequência por semana?

37. Quais os softwares usados no laboratório?

Figura 3 Questionários para diretores

Os alunos e professores da $13^{\mathrm{a}}$ Gerência Regional de Ensino gerenciada pela Secretaria de Educação do Estado da Paraíba constituem a população estudada. As cidades que fazem parte deste conjunto são de Pombal (zona urbana e rural), Cajazeirinhas, São Bentinho, Lagoa, Condado, Paulista, Vista Serrana e São Domingos. O tamanho da população dos professores e alunos foi obtido por informação dos diretores. Com isso, o total de professores informado é de 239 e de alunos é de 3718.

Os alunos e professores que responderam aos questionários foram aqueles presentes durante a aplicação do mesmo. De um total de 18 escolas desta gerência regional, 14 aceitaram participar e todos concordaram em realizar a aplicação dos questionários para os alunos. Como a participação no survey dependia da disponibilidade do participante, podemos classificar a amostra de 134 professores e 735 alunos como de conveniência. Não conseguimos uma lista completa dos professores e alunos de todas as escolas, o que impossibilitou identificar os indivíduos da população e escolher uma amostra aleatória. Com isso, nossa amostra é multiestágio e sem estratificação. A quantidade de questionários enviados e respondidos em cada escola é mostrada na Tabela 1 .

A amostra é considerada estatisticamente válida porque corresponde a 56,07\% dos professores e $17,62 \%$ dos alunos, perfazendo um número maior que $10 \%$ da população [7]. De posse dos questionários, desprezamos aqueles que não tinham todas as perguntas respondidas, sendo este o nosso método de descarte. Com isso, rejeitamos 5 questionários de professores e 69 questionários de alunos, reduzindo as amostras de alunos e professores para 666 e 129 , respectivamente.

As seguintes questões descritivas são exploradas neste survey: (1) Como os professores e alunos são avaliados em conhecimentos de informática? (2) Qual o nível de infraestrutura computacional disponível para os professo- res e alunos? (3) Como os professores e alunos usam os computadores durante as aulas? Com isso, foram identificadas as variáveis independentes "conhecimento em informática" e "infraestrutura de informática disponível", além da variável dependente "uso dos computadores". Convencionamos que cada variável poderia assumir o valor alto ou baixo.

A conversão entre os pontos obtidos nos questionários e o nível de cada variável estatística foi feita utilizando a escala Likert, atribuindo o valor 1 para a resposta "sim", 0 para a resposta "não" nos questionários dos professores e diretores, e valores variando de 0 a 4 para as respostas que vão de discordo totalmente a concordo totalmente nos questionários dos alunos. A partir daí, cada variável correspondeu a um conjunto específico de questões de mesmo peso e a resposta de cada uma foi somada cumulativamente, gerando um valor total para cada variável estatística. Para relacionar os números obtidos nesta soma aos valores alto ou baixo, efetuamos a soma dos pontos correspondentes às respostas de todas as questões. Com este resultado, obtivemos a soma máxima atingida, dividimos este valor pela metade e convencionamos que todos os questionários cuja soma de respostas fosse menor ou igual a este valor, teria a variável estatística de valor baixo.

As variáveis estatísticas foram escolhidas pelos pesquisadores na fase de planejamento estatístico. $\mathrm{Na}$ sequência, os questionários foram criados visando à determinação da relação estatística e descritiva destas variáveis. A variável independente "Conhecimento em informática" foi considerada usando o conjunto de questões do survey dos professores de 25 a 29 e 32, além das questões 1 a 8 do questionário dos alunos. Na sequência, a variável "Infraestrutura de informática" foi analisada a partir das questões 17, 18, 20, 23, 24, 26, 30, 31 do survey dos professores e 33 a 37 do survey dos diretores e 9 a 11 do survey dos alunos. A variável dependente "Uso dos computadores" é composta pela análise das respostas das questões 19, 20 e 21 do survey dos professores e 12 a 16 do survey dos alunos. A Tabela 2 mostra a relação entre as variáveis estatísticas e os itens dos questionários aplicados, assim como os assuntos abordados em cada grupo de questões. Para fins de simplificação desta tabela, consideramos que as questões dos questionários dos diretores fazem parte do questionário dos professores. 


\begin{tabular}{|c|c|c|c|c|c|}
\hline & & Professores & & Alunos & \\
\hline Cidade & Escola & \# Total & \%Recebidos & \# Total & $\%$ Recebidos \\
\hline \multirow[t]{9}{*}{ Pombal } & EEFM. Arruda Câmara & 38 & $50,00 \%$ & 532 & $25,94 \%$ \\
\hline & EEEF. João da Mata & 34 & $35,29 \%$ & 180 & $17,22 \%$ \\
\hline & EEEMP. Mons. Vicente Freitas & 20 & $95,00 \%$ & 797 & $6,15 \%$ \\
\hline & EEEF. Oito de Julho & 13 & $53,85 \%$ & 20 & $85,00 \%$ \\
\hline & EEEF. Joana Ivonildes Bandeira & - & - & 100 & $11,00 \%$ \\
\hline & EEEF. Amelia Maria da Luz & 13 & $46,15 \%$ & 100 & $19,00 \%$ \\
\hline & EEEF. Estrelo & 2 & $100,00 \%$ & 13 & $84,62 \%$ \\
\hline & EEEF. Pedra Branca & 2 & $100,00 \%$ & 12 & $25,00 \%$ \\
\hline & EEEF de Mundo Novo & - & - & 12 & $100,00 \%$ \\
\hline Cajazeirinhas & EEEF. Ma Soledade Freitas & 14 & $64,29 \%$ & 103 & $24,27 \%$ \\
\hline São Bentinho & EEEFM. Levi Olímpio Ferreira & 18 & $66,67 \%$ & 286 & $28,67 \%$ \\
\hline \multirow[t]{2}{*}{ Lagoa } & EEEFM. Frei Bruno & 9 & $44,44 \%$ & 175 & $18,86 \%$ \\
\hline & EEEF. Mons. Valeriano Pereira & - & - & 314 & $20,70 \%$ \\
\hline \multirow[t]{2}{*}{ Condado } & EEEF. Dr. José Queiroga & 17 & $52,94 \%$ & 320 & $15,94 \%$ \\
\hline & EEEMP. Dr. Trajano Pires da Nóbrega & - & - & 232 & $9,05 \%$ \\
\hline Paulista & EEEFM. Fa De Sá Cavalcante & 19 & $42,11 \%$ & 210 & $20,00 \%$ \\
\hline Vista Serrana & EEEFM. Manoel Medeiros & 22 & $72,73 \%$ & 248 & $13,31 \%$ \\
\hline \multirow[t]{2}{*}{ São Domingos } & EEEFM. Cícero Severo Lopes & 18 & $50,00 \%$ & 126 & $15,87 \%$ \\
\hline & & & $56,07 \%$ & 3780 & $17,62 \%$ \\
\hline
\end{tabular}

Tabela 1 Quantificação de questionários por escolas

\begin{tabular}{|c|c|c|c|}
\hline Nome da variável & Pergunta de pesquisa & $\begin{array}{l}\text { Item do survey para profes- } \\
\text { sores }\end{array}$ & Item do survey para alunos \\
\hline $\begin{array}{l}\text { Variável independente } 1: \\
\text { Conhecimento em informá- } \\
\text { tica }\end{array}$ & $\begin{array}{l}\text { Questão de pesquisa des- } \\
\text { critiva 1: Como os profes- } \\
\text { sores são avaliados em } \\
\text { conhecimento de informá- } \\
\text { tica? }\end{array}$ & $\begin{array}{l}\text { Vide questões } 25,27,28, \\
29 \text { e } 32 \text { : Conceitos básicos, } \\
\text { dificuldades ao usar com- } \\
\text { putadores e experiência em } \\
\text { suítes de escritório. }\end{array}$ & $\begin{array}{l}\text { Vide questões } 1 \text { a } 8 \text { : Con- } \\
\text { ceitos básicos, uso de edi- } \\
\text { tores de texto, navegadores } \\
\text { e redes sociais. }\end{array}$ \\
\hline $\begin{array}{l}\text { Variável independente } 2 \text { : } \\
\text { Infraestrutura de informáti- } \\
\text { ca }\end{array}$ & $\begin{array}{l}\text { Questão de pesquisa des- } \\
\text { critiva 2: Qual o nível de } \\
\text { infraestrutura computacio- } \\
\text { nal disponível? }\end{array}$ & $\begin{array}{l}\text { Vide questões } 17,18,20, \\
23,24,26,30,31 \text { e } 33 \text { a } \\
37: \text { Disponibilidade de } \\
\text { computadores, acesso à } \\
\text { Internet e cursos de capaci- } \\
\text { tação em informática. }\end{array}$ & $\begin{array}{l}\text { Vide questões } 9 \text { a 11: Dis- } \\
\text { ponibilidade de computa- } \\
\text { dores, acesso à Internet e } \\
\text { cursos de capacitação em } \\
\text { informática. }\end{array}$ \\
\hline $\begin{array}{l}\text { Variável dependente } 1: \\
\text { Uso dos computadores }\end{array}$ & $\begin{array}{l}\text { Questão de pesquisa des- } \\
\text { critiva 3: Como os profes- } \\
\text { sores usam os computado- } \\
\text { res durante as aulas? }\end{array}$ & $\begin{array}{l}\text { Vide questões } 19,21 \text { e } 22 \text { : } \\
\text { Levantamento de dificul- } \\
\text { dades que impedem o uso } \\
\text { dos computadores nas } \\
\text { aulas. }\end{array}$ & $\begin{array}{l}\text { Vide questões } 12 \text { a } 16 \text { : Uso } \\
\text { dos computadores para } \\
\text { atividades de sala de aula e } \\
\text { uso do celular. }\end{array}$ \\
\hline
\end{tabular}

Tabela 2 Correspondência entre variáveis estatísticas, perguntas de pesquisa e questões dos surveys. 
Adicionalmente, são propostas as seguintes questões de inferência: (4) O nível de conhecimento dos professores e alunos em informática é relacionado ao uso dos computadores durante as aulas? (5) A infraestrutura de informática oferecida pelas escolas afeta o uso dos computadores pelos professores e alunos durante as aulas? (6) A infraestrutura das escolas está relacionada ao conhecimento em informática dos alunos e professores? Como as três variáveis envolvidas são categóricas e pretendemos investigar a associação entre duas variáveis estatísticas por questão, usamos o teste chi-quadrado com o auxílio do software estatístico R. Adicionalmente, usamos $\alpha$ igual a 5\% para todas as análises e análise log-linear para investigar a associação entre as três variáveis ao mesmo tempo.

Para identificar as ameaças à validade [4], identificamos a validade interna de história, uma vez que aplicamos os questionários dos professores e dos alunos em momentos diferentes. Além disso, também identificamos a validade interna de seleção, pois a seleção dos participantes não foi feita aleatoriamente entre os estratos, sendo adotada uma amostra de conveniência. Não identificamos ameaças à validade de construção ou de conclusão.

Outras ameaças à validade do trabalho envolvem restrições de tempo e limitações decorrentes da redação das perguntas dos questionários dos alunos. Devido ao tempo demandado à aplicação dos questionários e restrições orçamentárias, não fizemos testes de campo. Além disso, entendemos que a redação das perguntas deveria ter sido afirmativa. Por exemplo, a questão "Você possui computador em casa?" deveria ser "Possuo computador em casa." com o objetivo de que as respostas da escala Likert (concordo totalmente a discordo totalmente) fossem coerentes a estas perguntas. Com isso, há a possibilidade de que a elaboração das perguntas gere viés aos respondentes. Mesmo assim, para aumentar a confiabilidade dos dados obtidos, a compilação dos resultados foi manual e conferida por 3 pessoas, pois os questionários eram impressos.

\section{Resultados}

Para responder as questões descritivas, mostramos os gráficos dos dados coletados. Como não encontramos pesquisas relacionadas a alguns dados descritos e os gráficos mostrados nesta seção não apresentam valores exatos, entendemos que esta seria uma contribuição relevante deste artigo. Por isso, alguns dados não possuem comparações com dados prévios de outras pesquisas, mas ainda assim são descritos. Iniciamos mostrando o perfil inicial dos professores com relação ao tempo em que eles trabalharam na escola.

Com relação aos anos trabalhados pelos professores, oferecemos respostas em intervalos, com as seguintes frequências absolutas sendo observadas: 19 professores na faixa de menos de um ano, 41 professores na faixa de um a três anos, 22 professores na faixa de três a cinco anos e 47 professores na faixa de mais de cinco anos. A Figura 4 mostra o gráfico destes resultados.

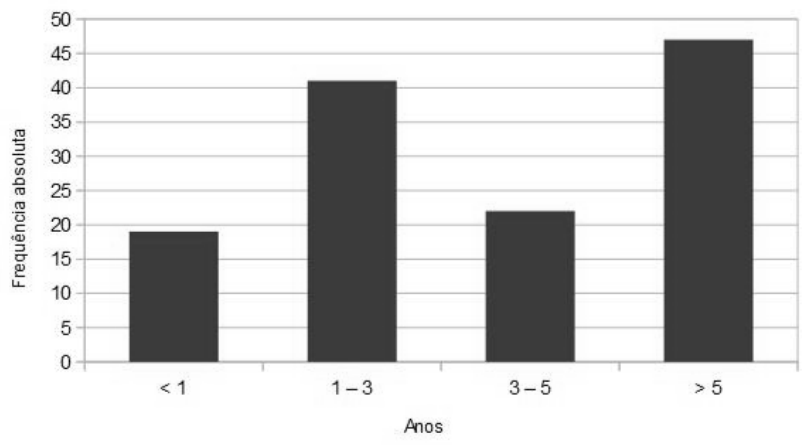

Figura 4 Anos de trabalho dos professores nas escolas

Com relação às idades dos alunos, observou-se que a maior incidência se encontra na faixa dos 11 aos 20 anos. Mais especificamente, a maior frequência absoluta de 114 ocorrências $(17,12 \%)$ equivale aos alunos com idade de 16 anos. Em segundo lugar, 102 alunos (15,31\%) possuem idade de 17 anos e 80 alunos (12,01\%) possuem idade de 15 anos. Dentre as menores ocorrências, encontram-se os alunos com 5 e 23 a 36 anos, perfazendo no máximo 1 ocorrência. Comparando com os dados obtidos pela média nacional apresentados pela pesquisa do CGI.Br [2], constamos que estes são menores em 5,67\% para a faixa etária de até 13 anos, 7,68\% para a faixa entre 14 e 15 anos e maiores em $24,36 \%$ para a faixa de 16 ou mais anos. A Figura 5 mostra o gráfico de barras com estes resultados.

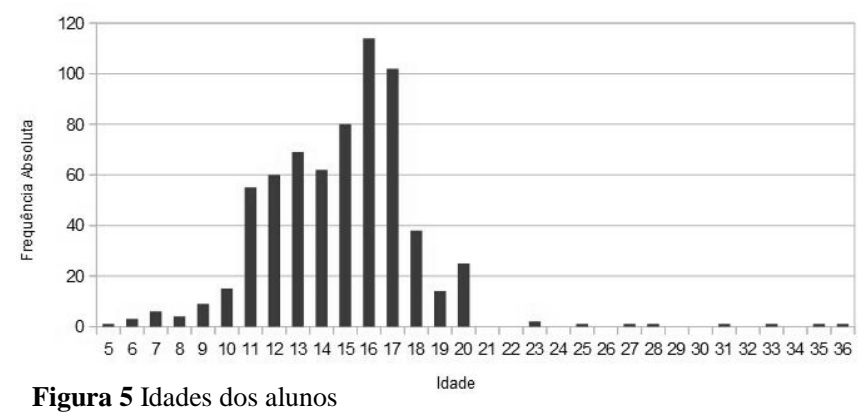


No que diz respeito ao sexo dos alunos, verificou-se que há 365 alunos do sexo feminino e 301 do sexo masculino. Com isso, há uma prevalência do sexo feminino em relação ao masculino. Se comparado às pesquisas realizadas pelo CGI.Br no Brasil em 2014, concluímos que eles são maiores em $1,80 \%$ dos dados de nossa pesquisa em relação ao público feminino. A Figura 6 mostra o gráfico de barras que ilustra este resultado.

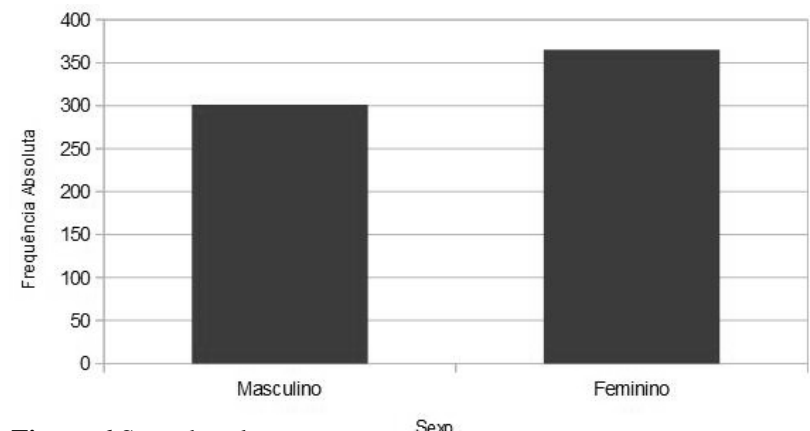

Figura 6 Sexo dos alunos

Para responder as questões referentes à infraestrutura das escolas, entrevistamos todos os diretores, totalizando 20 entrevistados. A questão 33 informou que 13 escolas possuem laboratório de informática. Ademais, a questão 34 informa que 8 escolas possuem acesso à Internet, ao passo que 10 escolas possuem funcionários alocados para o conserto dos computadores (questão 35) e 12 escolas oferecem acesso aos computadores pelos alunos (questão 36). As escolas que possuem laboratórios de informática usam o sistema operacional Linux e suas distribuições, como o Linux Educacional. Somente 2 escolas do total de 20 usam o sistema operacional Windows.

Dentre as escolas que possuem laboratório (item a da questão 33), 7 possuem entre 1 e 10 computadores, 12 possuem entre 11 e 20 , nenhuma possui entre 21 e 30 computadores, 3 escolas possuem entre 31 a 40 computadores, 1 escola possui entre 40 e 50 computadores e 1 possui mais de 51 computadores no laboratório. A Figura 7 mostra o gráfico em barras para a quantidade de computadores nas escolas.

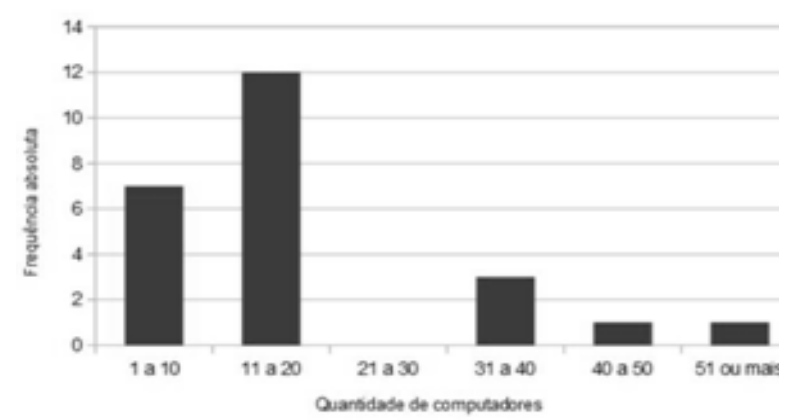

Figura 7 Quantidade de computadores nos laboratórios
Sobre a frequência de uso do laboratório pelos alunos, 13 escolas afirmaram que seus professores levam os alunos ao laboratório diariamente, enquanto nenhuma afirma que o professor conduz os alunos ao laboratório duas vezes por semana, 5 escolas têm professores que levam os alunos para o laboratório uma vez por semana e 9 escolas afirmam ter professores que nunca levam os alunos ao laboratório. A Figura 8 mostra o gráfico que resume os dados sobre a frequência de uso dos laboratórios.

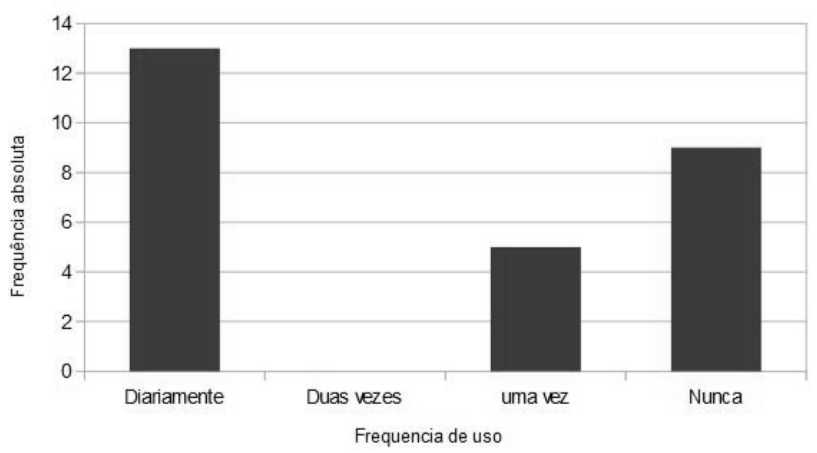

Figura 8 Frequência de uso do laboratório de informática

Quando comparado aos dados do TIC Educação 2014, $61,54 \%$ dos entrevistados possui acesso à Internet oferecido pela escola, o que gera uma diminuição de $30,46 \%$ em relação aos dados divulgados para as escolas no Brasil. Além disso, somente $50 \%$ das escolas em nossa pesquisa disponibilizam funcionários alocados para suporte na área de informática, em contrapartida aos $88 \%$ informados na pesquisa nacional. O gráfico contendo as frequências das respostas é mostrado na Figura 9.

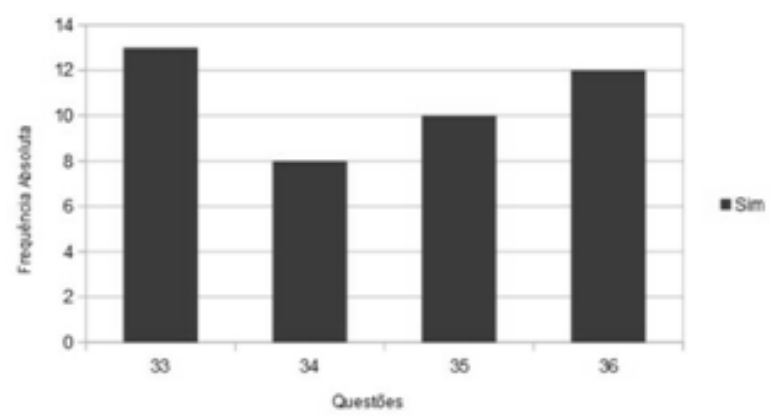

Figura 9 Respostas dos questionários dos diretores

O questionário aplicado aos professores teve 129 entrevistados e era composto de questões dicotômicas ( $\mathrm{sim} /$ não). Os resultados de cada questão estão citados por ordem, a saber: 125 professores informaram que têm computador em casa, 129 professores possuem acesso à Internet, 103 professores usam os computadores durante suas aulas e 103 informam que o computador ao qual eles 
têm acesso é de fácil disponibilidade. Seguindo para a questão 5 , continuamos em ordem: 35 professores usam o laboratório de informática frequentemente em suas aulas, 98 professores afirmam que os alunos colaboram com as atividades desenvolvidas no laboratório de informática, 129 afirmam que a participação dos professores em cursos ou oficinas é importante e que há disponibilidade deles para cursos de capacitação (questões 7 e 8), 38 têm dificuldade de usar o computador e 96 respondentes já participaram de cursos de informática anteriormente. Na sequência, a questão 11 informa que 97 professores já redigiu provas ou textos usando o computador, 58 preparam slides para exibir conteúdos escolares, 44 afirmam ter conhecimento técnico em computadores, 29 informam que há programas de inclusão digital na escola, 30 professores informam ter passado por cursos de capacitação e 129 afirmaram que a inclusão digital pode melhorar o desempenho docente e discente. A Figura 10 mostra o gráfico contendo as respostas do questionário submetido aos professores.

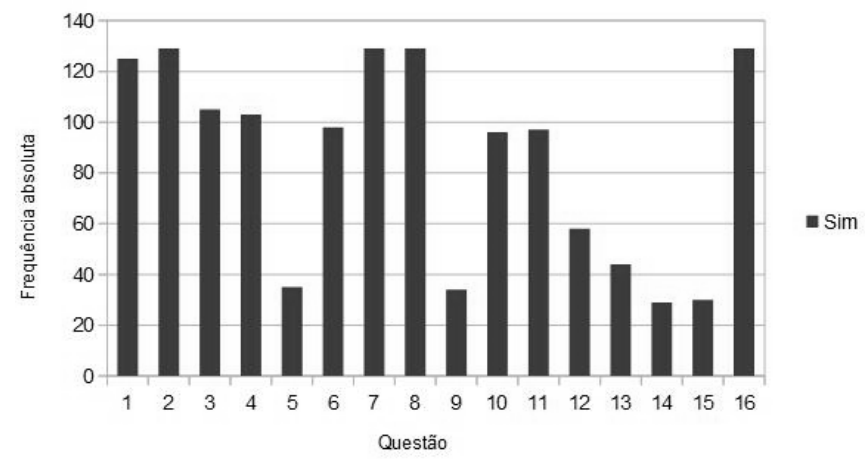

Figura 10 Respostas dos questionários dos professores

O questionário dos alunos teve 666 entrevistados e oferecia respostas com escalas de 5 níveis. Dentre os resultados de cada questão, são citadas as maiores frequências de respostas de cada questão, em ordem: 236 alunos concordam totalmente que têm conhecimento sobre hardware, 270 alunos concordam totalmente que têm conhecimento de software, 221 alunos afirmam saber a diferença entre periféricos de entrada e saída, 243 alunos sabem organizar pastas e arquivos em um gerenciador de arquivos, 199 alunos afirmam não ter conhecimento na resolução de problemas técnicos de computadores, 242 alunos sabem editar textos, 442 alunos usam o celular com frequência, 313 alunos nunca participaram de cursos para usar o computador, 353 alunos possuem computador em casa, 372 alunos possuem acesso à Internet, 340 alunos possuem smartphone, 302 alunos usam o computador para fazer atividades da escola, 369 alunos não concordam que a frequência de uso do laboratório de informática é alta, 277 alunos afirmam que não fazem trabalhos na escola usando o computador, 366 alunos concordam que o celular deles é mais usado para acesso à Internet do que para fazer ligações e 323 alunos concordam que o uso do celular não atrapalha $\mathrm{o}$ aprendizado em sala de aula. A Figura 11 mostra os resultados da aplicação dos questionários dos alunos por questão e categoria.

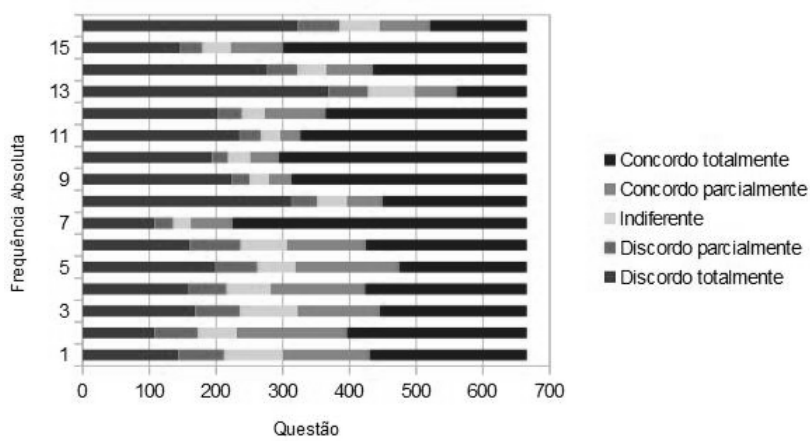

Figura 11 Respostas dos questionários dos alunos

Verificamos que $66 \%$ dos alunos afirmam usar o celular com frequência, $53,01 \%$ possui computador em casa, $55,85 \%$ possui acesso à Internet e $51,0 \%$ possui smartphone. Estas informações corroboram com os dados dos alunos da pesquisa TIC Educação 2014, que afirma que o maior uso das TIC está fora do ambiente escolar, ainda que a atividade realizada seja relacionada à educação formal.

As questões descritivas do survey foram respondidas a partir dos questionários aplicados aos professores e alunos. Estas questões não foram usadas para definir as variáveis estatísticas, pois elas foram escolhidas pelos pesquisadores na fase de planejamento estatístico, quando os questionários ainda não tinham sido elaborados. Apresentamos as seguintes respostas para estas questões:

\section{(1) Como os professores e alunos são avaliados em relação ao conhecimento de informática?}

Para os professores, o conhecimento alto excede o conhecimento baixo em $30,24 \%$, pois 84 de 129 professores declararam informações que levaram ao enquadramento nesta categoria. Apesar da maioria dos professores afirmar ter dificuldade em usar o computador e não possuir conhecimento técnico, mais da metade deles já usou suítes de escritório. Ademais, todos afirmam que a inclusão digital é capaz de melhorar o desempenho discente e docente.

Para os alunos, o conhecimento alto representa 415 de um total de 666 questionários, representando $62,31 \%$ dos entrevistados. A partir daí, é possível constatar que o 
número de alunos com conhecimento alto representa mais do dobro de alunos com conhecimento baixo. De fato, 366 alunos afirmaram concordar parcialmente ou totalmente que tinham conhecimento sobre hardware, 435 alunos têm conhecimento sobre software e 504 alunos afirmam usar com muita frequência aplicativos em seus smartphones.

\section{(2) Qual o nível da infraestrutura computacional disponível para alunos e professores?}

As informações dos professores e alunos diziam respeito à infraestrutura acessível dentro e fora da escola. Para os professores, verificamos que a infraestrutura alta é disponível para 86 respondentes, representando $66,67 \%$ do total. Observou-se que a maioria dos professores têm computador em casa com acesso à Internet, além do acesso ao computador na escola ser de fácil disponibilidade. Ademais, a maioria afirma que não há capacitação disponível na área de informática e estes se mostraram disponíveis em participar dessa atividade. Em contrapartida, a maioria das escolas não possui funcionários alocados para o conserto dos computadores.

A infraestrutura disponível aos alunos coincide com a dos professores somente com relação ao ambiente da escola. Fora da escola, as condições são outras, então os resultados em relação a esta variável estatística não são os mesmos. A infraestrutura alta teve 442 ocorrências, representando $66,37 \%$ do total de questionários. Isto equivale ao dobro da quantidade representada pela baixa infraestrutura. Um total de 387 respondentes concordam totalmente ou parcialmente que possui computador em casa. Além disso, 415 alunos concordam totalmente ou parcialmente que possuem acesso à Internet, mesmo que não seja proveniente da escola. Em adição, 415 alunos possuem smartphones.

\section{(3) Como os professores e alunos usam os computa- dores durante as aulas?}

Com relação aos professores, a maioria informou que não usa os computadores durante as aulas. Adicionalmente, eles afirmaram que a maioria dos alunos colabora com as atividades desenvolvidas no laboratório, mas a minoria dos professores realiza aulas no laboratório frequentemente. Usando o software estatístico $\mathrm{R}$, verificamos que existem 79 ocorrências para o uso baixo e 50 para uso alto, o que leva o uso do computadores a ser predominantemente baixo. Também observou-se que o uso dos com- putadores aumenta com a infraestrutura alta ou conhecimento alto.

Já no que diz respeito aos alunos, o baixo uso dos computadores representa 359 ocorrências, gerando uma diferença de apenas 52 ocorrências, ou 7,81\%, em relação ao alto uso. Provavelmente, esta pouca diferença é ocasionada pelo baixo poder aquisitivo dos alunos quando comparados aos professores. É possível observar que a infraestrutura alta é mais representativa quando o uso é alto e o conhecimento é alto. Para o uso baixo, há mais ocorrências de infraestrutura alta e conhecimento baixo. Dentre os alunos respondentes, 393 concordam totalmente ou parcialmente que usam o computador para fazer atividades da escola. Além disso, 444 alunos concordam totalmente ou parcialmente que usam o celular mais para acesso à Internet do que para fazer ligações. Segundo os alunos, o celular não atrapalha o aprendizado em sala de aula, com 385 respondentes informando que concordam totalmente ou parcialmente com esta afirmação. No entanto, somente 301 alunos informam que fazem trabalhos na escola com auxílio do computador e somente 169 respondentes afirmaram que a frequência com que eles assistem aulas no laboratório de informática é alta.

Com respeito às questões de inferência, usamos a análise log-linear que produziu um modelo final que não reteve todos os efeitos. A razão de verossimilhança deste modelo foi $\operatorname{chi}^{2}(0)=0$ e $p=1$. Estes testes foram realizados para os dados dos professores e repetidos para os dados dos alunos.

No que concerne aos professores, a mais alta ordem de interação (Uso dos computadores $x$ Infraestrutura $x$ Conhecimento) não é estatisticamente significante para $\operatorname{chi}^{2}(1)=0,06$ e p $=0,79$. Já com relação aos alunos, os valores obtidos foram $\mathrm{chi}^{2}(1)=0,001 \mathrm{e} \mathrm{p}=0,97$. Para investigar o efeito entre estas variáveis estatísticas, testes qui-quadrado separados foram feitos nas variáveis Infraestrutura e Uso dos computadores para Conhecimento alto e baixo, assim como para as variáveis Conhecimento e Uso dos computadores para Infraestrutura alta e baixa. Com isso, as respostas das questões de inferência são:

(4) O nível de conhecimento em informática dos professores e alunos é relacionado ao uso dos computadores durante as aulas? 
Para os professores com conhecimento alto, não houve associação significativa entre as variáveis Infraestrutura e Uso dos computadores, resultando em $\operatorname{chi}^{2}(1)=1,32$ e $p=0,25$. A razão de probabilidades indica que a chance do professor com conhecimento alto usar pouco os computadores é 1,72 vezes menor para a infraestrutura baixa em relação à alta. Além disso, a Tabela 3 mostra que a frequência de uso dos computadores baixa em sala de aula supera a alta em $28,57 \%$, ao passo que a infraestrutura alta supera a baixa em $35,72 \%$.

\begin{tabular}{l|c|c|c}
\hline & \multicolumn{3}{|l}{ Uso dos computadores } \\
\hline Infraestrutura & Alto & Baixo & Total (Linhas) \\
\hline Alta & 18 & 39 & $57(67,86 \%)$ \\
\hline Baixa & 12 & 15 & $27(32,14 \%)$ \\
\hline \multirow{2}{*}{ Total (colunas) } & 30 & 54 & \\
& $(35,71 \%)$ & $(64,28 \%)$ & 84
\end{tabular}

Tabela 3 Tabela de contingência para conhecimento alto (professores)

Para o conhecimento baixo dos professores, adquirimos $\operatorname{chi}^{2}(1)=0,31$ e $\mathrm{p}=0,57$, o que revelou que as variáveis são independentes. A Tabela 4 mostra que o baixo uso dos computadores excede o alto uso em $11,12 \%$ e os níveis de infraestrutura diferem em $28,88 \%$. A razão de probabilidade indica que a chance do professor de conhecimento baixo usar pouco os computadores é 1,41 vezes menor para a infraestrutura baixa do que para a alta.

\begin{tabular}{l|l|l|l}
\hline & \multicolumn{3}{|l}{ Uso dos computadores } \\
\hline Infraestrutura & Alto & Baixo & Total (linhas) \\
\hline Alta & 12 & 17 & $29(64,44 \%)$ \\
\hline Baixa & 8 & 8 & $16(35,56 \%)$ \\
\hline $\begin{array}{l}\text { Total (colu- } \\
\text { nas) }\end{array}$ & 20 & 25 & \\
\hline
\end{tabular}

Tabela 4 Tabela de contingência para conhecimento baixo (professores)

Para os alunos com conhecimento alto, não existiu associação significativa entre as variáveis Infraestrutura e Uso dos computadores, resultando nos valores $\operatorname{chi}^{2}(1)=2,88$ e $\mathrm{p}=0,089$. A frequência de uso dos computadores alta excede a baixa em $9,39 \%$, ao passo que a infraestrutura alta supera a baixa em $48,44 \%$. A razão de probabilidades indica que a chance de um aluno com conhecimento alto usar pouco o computador é de 1,46 vezes menor para a infraestrutura baixa em relação à alta. A Tabela 5 mostra as frequências para cada caso.

\begin{tabular}{l|l|l|l}
\hline & \multicolumn{3}{|l}{ Uso dos computadores } \\
\hline Infraestrutura & Alto & Baixo & Total (Linhas) \\
\hline Alta & 176 & 132 & $308(74,22 \%)$ \\
\hline Baixa & 51 & 56 & $107(25,78 \%)$ \\
\hline \multirow{3}{*}{ Total (colunas) } & 227 & 188 & \\
& $(54,69 \%)$ & $(45,30 \%)$ & 415
\end{tabular}

Tabela 5 Tabela de contingência para conhecimento alto (alunos)

Para os alunos com conhecimento baixo, também não existiu associação significativa entre a infraestrutura e o uso dos computadores, pois $\operatorname{chi}^{2}(1)=2,06$ e $\mathrm{p}$ $=0,15$. A Tabela 6 mostra que o uso baixo dos computadores supera o alto em $36,26 \%$, ao passo que a infraestrutura alta supera a baixa em somente $6,77 \%$. A razão de probabilidades indica que a chance de um aluno com conhecimento baixo usar pouco computadores é de 1,48 vezes menor para a infraestrutura baixa do que para a alta.

\begin{tabular}{l|l|l|l}
\hline & \multicolumn{3}{|l}{ Uso dos computadores } \\
\hline Infraestrutura & Alto & Baixo & Total (linhas) \\
\hline Alta & 48 & 86 & $134(53,38 \%)$ \\
\hline Baixa & 32 & 85 & $117(46,61 \%)$ \\
\hline & 80 & 171 & \\
Total (colunas) & $(31,87 \%)$ & $(68,13 \%)$ & 251 \\
\hline
\end{tabular}

Tabela 6 Tabela de contingência para conhecimento baixo (alunos)

\section{(5) A infraestrutura de informática oferecida pelas escolas afeta o uso dos computadores pelos profes- sores e alunos durante as aulas?}

Para os professores e uma alta infraestrutura, o uso dos computadores e o conhecimento não apresentaram associação significativa. Com isso, $\operatorname{chi}^{2}(1)=0,81 \mathrm{e} \mathrm{p}=$ 0,37 . Os resultados das razões de probabilidades informaram que a chance do professor com disponibilidade de infraestrutura alta usar pouco os computadores é 1,52 vezes menor para o professor com conhecimento baixo em relação ao alto. A Tabela 7 mostra que o baixo uso dos computadores excede o alto uso em $30,24 \%$, ao passo que o conhecimento alto excede o baixo em $32,56 \%$.

\begin{tabular}{l|c|c|c}
\hline & \multicolumn{3}{|c}{ Uso dos computadores } \\
\hline Conhecimento & Alto & Baixo & Total (linhas) \\
\hline Alto & 18 & 39 & $57(66,28 \%)$ \\
\hline Baixo & 12 & 17 & $29(33,72 \%)$ \\
\hline \multirow{2}{*}{ Total (colunas) } & 30 & 56 & \\
& $(34,88 \%)$ & $(65,12 \%)$ & 86
\end{tabular}

Tabela 7 Tabela de contingência para infraestrutura alta (professores) 
Para a baixa infraestrutura em informática submetida aos professores, obtivemos $\operatorname{chi}^{2}(1)=0,12$ e $\mathrm{p}=$ 0,72 , o que mostra que as variáveis são independentes. A razão de probabilidades informa que a chance do professor submetido a uma baixa infraestrutura usar pouco os computadores é 1,24 vezes menor para o conhecimento baixo do que para o alto. A Tabela 8 mostra que o uso baixo dos computadores excede o alto em $6,98 \%$, enquanto que o conhecimento alto supera o baixo em $25,58 \%$.

\begin{tabular}{l|c|c|c}
\hline & \multicolumn{3}{|c}{ Uso dos computadores } \\
\hline Conhecimento & Alto & Baixo & Total (linhas) \\
\hline Alto & 12 & 15 & $27(62,79 \%)$ \\
\hline Baixo & 8 & 8 & $16(37,21 \%)$ \\
\hline Total (colunas) & 20 & 23 & \\
$(46,51 \%)$ & $(53,49 \%)$ & 43
\end{tabular}

Tabela 8 Tabela de contingência para infraestrutura baixa (professores)

Para os alunos submetido a uma alta infraestrutura, houve associação significativa entre as variáveis Conhecimento em informática e Uso dos computadores. Obtivemos os valores $\operatorname{chi}^{2}(1)=16,983$ e $\mathrm{p}=3,77 \times 10^{-5}$. Também é possível constatar que o conhecimento alto supera o baixo em $39,37 \%$ e o alto uso dos computadores supera o baixo em $10,36 \%$. A razão de probabilidades evidencia que a chance de um aluno com disponibilidade de infraestrutura alta usar pouco os computadores é 2,38 vezes menor para o aluno com conhecimento baixo em relação ao alto. A Tabela 9 mostra a tabela de contingência para os alunos com alta infraestrutura.

\begin{tabular}{l|c|c|c}
\hline & \multicolumn{3}{|c}{ Uso dos computadores } \\
\hline Conhecimento & Alto & Baixo & Total (linhas) \\
\hline Alto & 176 & 132 & $308(69,683 \%)$ \\
\hline Baixo & 48 & 86 & $134(30,317 \%)$ \\
\hline \multirow{2}{*}{ Total (colunas) } & 224 & 218 & \\
& $(50,68 \%)$ & $(40,32 \%)$ & 442
\end{tabular}

Tabela 9 Tabela de contingência para infraestrutura alta (alunos)

Quando os alunos dispõem de baixa infraestrutura computacional, as variáveis Conhecimento em informática e Uso dos computadores apresentam associação significativa, $\operatorname{com} \operatorname{chi}^{2}(1)=9,89$ e $\mathrm{p}=0,002$. Ademais, a Tabela 10 informa que o baixo uso dos computadores supera o alto em $25,89 \%$ e o baixo conhecimento supera o alto em $4,46 \%$. A razão de probabilidades afirma que a chance de um aluno submetido a uma baixa infraestrutura usar pouco os computadores é 2,41 vezes menor para o conhecimento baixo do que para o alto.

\begin{tabular}{l|c|c|c}
\hline & \multicolumn{3}{|c}{ Uso dos computadores } \\
\hline Conhecimento & Alto & Baixo & Total (linhas) \\
\hline Alto & 51 & 56 & $107(47,77 \%)$ \\
\hline Baixo & 32 & 85 & $117(52,23 \%)$ \\
\hline & 83 & 141 & \\
Total (colunas) & $(37,05 \%)$ & $(62,94 \%)$ & 224
\end{tabular}

Tabela 10 Tabela de contingência para infraestrutura baixa (alunos)

(6) A infraestrutura de informática oferecida pelas escolas é relacionada ao conhecimento dos professores e alunos?

Para os professores com uso alto dos computadores, não houve associação significativa entre as variáveis Conhecimento em informática e Infraestrutura. Obtivemos os valores de $\operatorname{chi}^{2}(1)=0$ e $p=1$. Além disso, o alto conhecimento difere do baixo em $20 \%$, com o mesmo resultado entre a alta e baixa infraestrutura. A razão de probabilidades informa que a chance de um professor com alto uso dos computadores ter uma baixa infraestrutura é igual a para o professor com conhecimento baixo e alto. A Tabela 11 mostra a tabela de contingência para o alto uso dos computadores.

\begin{tabular}{l|c|c|c}
\hline & \multicolumn{3}{|l}{ Infraestrutura } \\
\hline Conhecimento & Alto & Baixo & Total (linhas) \\
\hline Alto & 18 & 12 & $30(60 \%)$ \\
\hline Baixo & 12 & 8 & $20(40 \%)$ \\
\hline Total (colunas) & $\begin{array}{c}30 \\
(60 \%)\end{array}$ & $\begin{array}{c}20 \\
(40 \%)\end{array}$ & 50
\end{tabular}

Tabela 11 Tabela de contingência para uso alto (professores)

Dentre os professores que usam pouco os computadores, também foi possível constatar que não há associação significativa entre as variáveis Conhecimento e Infraestrutura, pois $\operatorname{chi}^{2}(1)=0,15$ e $p=0,70$. A razão de probabilidades mostra que a chance de um professor que usa pouco o computador ter uma baixa infraestrutura é 1,22 vezes menor para o aluno com conhecimento baixo em relação ao alto. Além disso, a alta infraestrutura supera a baixa em $41,78 \%$, ao passo que o alto conhecimento supera o baixo em $36,70 \%$ (Tabela 12 ).

\begin{tabular}{l|c|c|c}
\hline & \multicolumn{3}{|l}{ Infraestrutura } \\
\hline Conhecimento & Alto & Baixo & Total (linhas) \\
\hline Alto & 39 & 15 & $54(68,35 \%)$ \\
\hline Baixo & 17 & 8 & $25(31,65 \%)$ \\
\hline \multirow{3}{*}{ Total (colunas) } & 56 & 23 & \\
$(70,89 \%)$ & $(29,11 \%)$ & 79
\end{tabular}

Tabela 12 Tabela de contingência para uso baixo (professores) 
Com relação aos alunos que usam muito os computadores, houve associação significativa entre as variáveis Conhecimento em informática e Infraestrutura, resultando em $\operatorname{chi}^{2}(1)=9,22$ e $p=0,002$. A Tabela 13 mostra que os alunos com alto conhecimento excedem aqueles com baixo conhecimento em $47,88 \%$ e aqueles submetidos à alta infraestrutura supera a baixa em $45,92 \%$. Além disso, a razão de probabilidades indica que a chance dos alunos que usam muito os computadores terem uma baixa infraestrutura é de 2,29 vezes menor para o aluno com conhecimento baixo em relação ao alto.

\begin{tabular}{l|c|c|c}
\hline & \multicolumn{3}{|l}{ Infraestrutura } \\
\hline Conhecimento & Alto & Baixo & Total (linhas) \\
\hline Alto & 176 & 51 & $227(73,94 \%)$ \\
\hline Baixo & 48 & 32 & $80(26,06 \%)$ \\
\hline \multirow{2}{*}{ Total (colunas) } & 224 & 83 & \\
$(72,96 \%)$ & $(27,04 \%)$ & 307
\end{tabular}

Tabela 13 Tabela de contingência para uso alto (alunos)

Da mesma forma, os dados dos alunos que usam pouco os computadores resultaram em uma associação significativa para as variáveis Conhecimento em informática e Infraestrutura. $\mathrm{O}$ teste chi-quadrado resultou em $\operatorname{chi}^{2}(1)=14,89$ e $p=0,0001$. A Tabela 14 mostra que a alta infraestrutura excede a baixa em $21,45 \%$ e o alto conhecimento supera o baixo em apenas $4,74 \%$. Ademais, a razão de probabilidades informa que a chance de um aluno que usa pouco o computador ser submetido a uma baixa infraestrutura é 2,32 vezes menor para o aluno com conhecimento baixo em relação ao alto.

\begin{tabular}{l|c|c|c}
\hline & \multicolumn{3}{|l}{ Infraestrutura } \\
\hline Conhecimento & Alto & Baixo & Total (linhas) \\
\hline Alto & 132 & 56 & $188(52,37 \%)$ \\
\hline Baixo & 86 & 85 & $171(47,63 \%)$ \\
\hline \multirow{2}{*}{ Total (colunas) } & $\begin{array}{c}218 \\
(60,72 \%)\end{array}$ & $\begin{array}{c}141 \\
(39,27 \%)\end{array}$ & 359
\end{tabular}

Tabela 14 Tabela de contingência para uso baixo (alunos)

\section{Conclusões}

Este trabalho visa definir o perfil de uso dos computadores de professores e alunos em 6 cidades do Sertão Paraibano. Para isso, aplicamos 134 questionários para professores, 20 questionários para diretores e 735 questionários para alunos de escolas de ensino fundamental e médio. Com isso, conseguimos estudar a relação entre as variáveis estatísticas Infraestrutura, Conhecimento em informática e Uso dos computadores dos alunos e professores destas instituições.

A análise entre as variáveis estatísticas foi realizada para os dados dos alunos e professores, mas só houve associação significativa entre o uso dos computadores e o conhecimento para os alunos. Além disso, descobrimos para os alunos que o uso dos computadores é relacionado a uma alta infraestrutura e alto conhecimento em informática e que o conhecimento é relacionado a um alto uso dos computadores e alta infraestrutura. Para os professores, o uso dos computadores está relacionado a uma alta infraestrutura e alto conhecimento em informática. Mesmo assim, a frequência de uso dos computadores para os professores é baixa, diminuindo com a alta infraestrutura ou o alto conhecimento.

Ainda constatamos os seguintes dados sobre os professores: a maioria trabalha 5 anos ou mais na escola e possui Internet e computador em casa. Com relação aos alunos, podemos observar que a maioria é feminina e tem idade entre 11 e 20 anos, com pouca vantagem em relação ao gênero masculino. A maioria dos alunos também concorda que o celular não atrapalha no desempenho em sala de aula, assistir aulas nos laboratórios de informática não é uma prática frequente e eles usam mais o celular para acessar a Internet do que para fazer ligações. Com relação aos laboratórios de informática das escolas, a maioria possui entre 10 e 20 computadores e seu uso é declarado pelos diretores como diário.

Os trabalhos futuros incluem a aplicação de questionários em outras cidades com o objetivo de ampliar a caracterização dos professores das escolas públicas do Alto Sertão da Paraíba. Também pretendemos promover cursos de capacitação para os professores e alunos e medir o desempenho dos participantes após os cursos. Ademais, entendemos que seria bastante pertinente a identificação e análise dos motivos para a baixa frequência de uso dos computadores nas escolas, baseado em dados identificados em trabalhos relacionados.

\section{Referências}

[1] Andrade, M., Borges, F., França, G., e Ramos, L. Impactos iniciais na formação dos professores e gestores para o uso do laptop educacional no estado do Tocantins. Inter Science Place, 1:126142, 2012.

[2] Comitê Gestor da Internet no Brasil. TIC Educação 2014. Disponível em http://cetic.br/publicacao/pesquisa-sobre-o-uso- 
das-tecnologias-de-informacao-e-comunicacaonas-escolas-brasileiras/. Abril de 2016.

[3] Costa, A. L. M. and Almeida, F. J. D. Condições materiais e a eficácia da informática aplicada à educação : a culpa é do professor? XVII Workshop de Informática na Educação (WIE), 2012.

[4] Creswell, J. W. Research design: Qualitative, quantitative, and mixed methods approaches. Sage publications, $4^{\mathrm{a}}$ edição, 2013.

[5] Damasceno, A., Diniz, A., Lopes, M., \& Albuquerque, R. Uso dos computadores nas escolas públicas do Alto Sertão da Paraíba. In Workshop de Informática na Escola (WIE) (Vol. 20, pp. 595-605), 2014. Prêmio de melhor artigo.

[6] Damasceno, A., Moreira, F., Santos, T., \& Alvino, C. Inclusão digital na cidade de Pombal. In Workshop sobre Educação em Informática (WEI), páginas 1689 - 1698. Natal - RN, 2011.

[7] Field, A., Miles, J., and Field, Z. Discovering statistics using R. Sage publications, $3^{\mathrm{a}}$ edição, 2012.

[8] Gomes, F. e Sá, R. Um Computador por Aluno em Araucária : investigando a prática dos professores. XVIII Workshop de Informática na Educação (WIE), 2012.

[9] Jeske, J. C., Silva, J., e Oliveira, R. Perfil da Informática na Educação nas Escolas Estaduais do Sudoeste Goiano. Workshop de Informática na Educação (WIE), páginas 1831-1836, 2009.

[10] Molin, S. I., \& Raabe, A. (2012). Novas Tecnologias n Educação: Transformações da Prática Pedagógica no Discurso Do Professor. XVIII Workshop de Informática na Educaçao (WIE).

[11] Nascimento, K. A. S., Lima, M. S., Freire, R., e Filho, J. A. C. Um olhar sobre as atividades dos laboratórios de informática educativa das escolas municipais de Fortaleza. XVII Workshop de Informática na Educação (WIE), páginas 1256 - 1263, 2011.

[12] Nobre, R. H., Sousa, J. A. de, \& Nobre, C. de S. Uso dos Laboratórios de Informática em Escolas do Ensino Médio e Fundamental no Interior Nordestino. Revista Brasileira de Informática na Educação, 23(3), páginas 70-80, 2015.

[13] Odorico, E. K., Nunes, D. M., Moreira, A., \& Oliveira, H. M. P. Análise do Não Uso do Laboratório de Informática nas Escolas Públicas e Estudo de Caso. XVIII Workshop de Educação Em Informática (WEI), 2012.

[14] Santos, D. A. d. N., Schlunzen, E. T. M., e Junior, K. S. Tecnologias educacionais na formação em serviço de professores: perspectivas para uma escola inclusiva. In Workshop de Informática na Escola (WIE), páginas 1498 - 1506, 2011.

[15] Silva, M. H. e Carvalho, L. M. T. L. A implementação do laboratório de informática na escola pública e o seu impacto no cotidiano escolar. Revista de Tecnologias (RETEC), 4(1):9-24, 2011.

[16] Valente, J. A. . O Computador Na Sociedade Do Conhecimento. Editora OEA_NIED/UNICAMP, 1999. 